\title{
Aproximaciones a la naturaleza en la India. El caso de Chipko Andolan
}

Lía Rodriguez de la Vega ${ }^{5}$

\section{Resumen}

El artículo considera sintéticamente el abordaje de la naturaleza y su relación con el género en la tradición india, para luego llegar al fenómeno de Chipko Andolan, el movimiento indio conocido por la imagen de mujeres aldeanas abrazadas a los árboles para evitar su tala, concluyendo con consideraciones desde distintas perspectivas, entre ellas, las del Ecofeminismo, que plantea una noción de identidad basada en la relación que cada individuo tiene con la inserción en el medio natural y conlleva una propuesta ética fundada en esa interrelación y en la valoración de la diferencia.

Palabras clave: Naturaleza- Género-Chipko Andolan- Ecofeminismo.

Recibido 9-2-2012 | Aprobado 27-5-2012

Institución. UNI-COM Facultad de Ciencias Sociales. Universidad Nacional de Lomas de Zamora. Argentina

liadelavega@yahoo.com

5 Experta en Hinduismo Yoga (USAL), Licenciada en Estudios Orientales (USAL), Dra. en Relaciones Internacionales (USAL), Estudios postdoctorales en la Universidad Federal de Rio Grande do Sul (UFRGS), Porto Alegre, Brasil. Coordinadora Nacional de la Asociación Latinoamericana de Estudios de Asia y África, Sección Argentina (2010-2012), miembro del Comité de Asuntos Asiáticos del Consejo Argentino para las Relaciones Internacionales (CARI) y Responsable del Área de Asia y África de UNICOM, Facultad de Ciencias Sociales, Universidad Nacional de Lomas de Zamora. 


\section{Approaches to nature in India. The case of Chipko Andolan}

\section{Abstract}

The article considers briefly the approach to nature and its relationship with gender in the Ancient Indian tradition, considering then the phenomenon of Chipko Andolan, the Indian movement known by the image of women hugging trees to prevent them from falling, concluding with considerations from different perspectives, among them, the one from Ecofeminism, which shapes a notion of identity based on the link between each individual and his/her insertion in the natural environment, that implies an ethical proposal based on which interaction and on the revalue of difference.

Keywords: Nature- Gender- Chipko Andolan- Ecofeminism. 


\section{Introducción}

"Los árboles protegen; protejámoslos"

Tirumala Tirupati, Andhra Pradesh, India.

(Narayanan, 1997)

El artículo trata sintéticamente el abordaje de la naturaleza y su relación con el género a través de la literatura védica y distintas corrientes de pensamiento no védicas en la India, aproximándonos luego, en ese contexto, a la historia, desarrollo y alcance del movimiento Chipko Andolan, surgido en defensa de los árboles en la zona del Himalaya, concluyendo con observaciones desde distintas perspectivas, que incluyen los planteos del Ecofeminismo ${ }^{6}$. El trabajo está basado en la consulta bibliografía de textos que se refieren a la temática y otros que son traducción directa del sánscrito al castellano e inglés de distintas fuentes indias?

\section{El abordaje de la naturaleza en la India}

Ya desde la India Antigua encontramos explícita la relación estrecha de los individuos con la naturaleza, como ocurre en otras culturas. La literatura Védica ${ }^{8}$, da muestra de ello a través de sus diferentes exponentes, entre ellos, himnos de los Vedas como por ejemplo los del Rig Veda, Al cielo y a la Tierra (V1, 70, 511), A la Aurora (V11, 77, 593), A Agni (X, 1), A las Aguas (X, 9, 835), A Surya-el Sol- (X, 37, 863), Al Sindhu- hoy, río Indo- ( X, 75, 901). Otro himno emblemático en este

6 "Ecofeminismo" alude a una pluralidad de posiciones que giran en torno al movimiento feminista occidental y el movimiento pacifista. Este término fue adoptado por primera vez en 1974, por Francoise d'Eaubonne, para referirse al potencial de las mujeres para llevar adelante una revolución ecológica que implicara nuevas relaciones de género, entre los seres humanos y la naturaleza (Carcaño Valencia, 2008)

7 Los términos sánscritos figuran transliterados a nuestro alfabeto pero no llevan otros signos diacríticos del idioma.

8 Ella comprende: a) Las Samhitas o colecciones (Rig Veda Samhita o Colección de los Himnos; Sama Veda Samhita o Colección de las Melodías; Yajur veda Samhita o Colección de Fórmulas rituales y Atharva Veda Samhita o Colección de los Himnos mágicos), b) los Brahmanas o Tratados de disquisiciones acerca del sacrificio, tanto simbólicas como rituales, c) los Aranyakas o Libros del Bosque y las Upanishads o Doctrinas secretas, con material similar al de los Brahmanas y también especulaciones de carácter filosófico. Ellos constituyen la literatura Sruti o sagrada revelada del Hinduismo, mientras que los textos denominados Sutras (que aluden a los distintos tipos de rituales) constituyen la literatura Smriti o recordada (Tola y Dragonetti, 1983; Lorenzen y Preciado Solís, 2003). 
sentido es el Himno a la Tierra o Prthivisukta $(X 11,1)$ del Atharva Veda (Tola, 1968; Olañeta, 2001):

En ella están océanos, ríos, aguas;

En ella se han originado

El alimento y los campos de cultivo.

En ella se agita lo que respira y tiene movimiento.

¿Qué la tierra nos de

la precedencia en la bebida!

$\ldots$

Envuélveme, oh, tierra, en el aroma

Que de ti constantemente brota,

En el que exhalan

Las platas y las aguas,

En el que hicieron suyo

Apsaras y Gandharvas.

Invocamos a la Tierra

Que sostiene todo, firme,

En que están fijamente establecidos

Los árboles y selvas. (Tola, 1968, pp. 156-176)

En la época Védica, el hombre realizaba sacrificios para ofrecérselos a los dioses, constituyendo estos sacrificios, y el ritual que ellos implicaban, el centro de la religión de ese momento. Existía una gran cantidad de ceremonias sacrifícales, desde las más sencillas hasta los ritos reales que exigían preparativos de hasta un año ${ }^{9}$ (Lorenzen y Preciado Solís, 2003). Los sacrificios podían ser de ofrendas de leche y vegetales, de víctimas animales y algunas veces humanas. Es decir, esa imbricación de la vida con el medio natural no implicaba el cuidado particular de ese medio sino que esa relación estrecha micro- macro cosmos estaba inserta en la lógica que implicaba la relación con las deidades y lo que era necesario realizar para pedir/obtener algo a/de ellos.

9 Aludimos al ashvameda o sacrificio del caballo, ritual de connotaciones políticas que otorgaba al soberano oferente soberanía sobre los otros monarcas, es decir, los territorios recorridos por el caballo (que luego sería sacrificado) durante un año, quedaban bajo la soberanía del oferente. Una descripción de este y otros ritos védicos puede encontrarse en Lorenzen y Preciado Solís (2003, pp. 31-36). 
En reacción a los sacrificios llevados adelante por el Brahmanismo ${ }^{10}$, el Budismo $^{11}$ se opuso a ellos y sosteniendo el principio de ahimsa (no violencia), contrapuso la norma budista de no matar seres vivos a la práctica sacrificial de los brahmanes ${ }^{12}$. Cabe señalar aquí que los distintos seres pueden tener diferentes encarnaciones, en razón de sus méritos o deméritos; así, los dioses, que en el Budismo tienen un papel secundario, pueden renacer como hombre, animal, etc., de igual manera que uno de ellos podría reencarnar como un dios.

También las Upanishads dan cuenta de la relación hombre-naturaleza:

La Aitareya Unpanishad ${ }^{13}$ (citada en Pujol, 2001) dice:

El fuego, transformado en habla, entró en la boca. El viento transformado en el aire de la respiración, entró en las fosas nasales. El sol, transformado en vista, entró en los ojos. Las regiones del espacio, transformadas en oído, entraron en las orejas. Las plantas y los árboles, transformados en pelos, entraron en la piel. La luna, transformada en mente, entró en el corazón. La muerte, transformada en el aire de la espiración, entró en el ombligo. El agua, transformada en semen, entró en el órgano viril.

Al tiempo que la Brhadaranyaka Unpanishad ${ }^{14}(3.2,13$, citada en Maillard, 2001) sostiene:

Yajñavalkya, cuando un hombre muere, su voz penetra en el fuego, su aliento en el viento, su vista en el sol, su mente en la luna, su oído en las regiones del espacio, su cuerpo en la tierra, su conciencia en el espacio, los pelos de su cuerpo en las plantas, sus cabellos en los árboles y su sangre y su semen se depositan en las aguas. Entonces, ¿dónde queda el hombre?

10 El Vedismo, el Brahmanismo y el Hinduismo propiamente dicho son las tres grandes manifestaciones de la corriente religiosa iniciada con la llegada de los indoeuropeos a la India y que continúa hasta hoy.

11 Esta doctrina, como sabemos, surgió con Siddharta Gautama o Buda, en el siglo VI A. C., quien predicó su mensaje durante 45 años y falleció (entró en el parinirvana) a los 80 años. Al respecto se puede consultar Rodríguez de la Vega (2008).

12 Para el Budismo, ahimsa representa uno de los diez preceptos y el primer elemento de su disciplina moral (sila). Es la primera norma que debe cumplir un bhikkhu (Dragonetti y Tola, 2004).

13 Vinculada con el Rig Veda, se ubica entre las Upanishads más antiguas, de entre 800-500 A.C.

14 Vinculada con el Yajur Veda "blanco", una de las dos recensiones del Yajur Veda, está también entre las Upanishads más antiguas. 
Esta relación mico-macrocosmos se verá también reflejada en el orden social con el surgimiento de las castas ${ }^{15}$, plasmado en el Purusha Sukta (Rig Veda, X, 90), himno que narra el sacrificio del Purusha, hombre gigante primordial, del que surgió toda la creación ${ }^{16}$ :

Su boca fue el brahmán,

Sus dos brazos el guerrero,

Sus muslos el vaishya,

De sus pies nació el sudra.

De su ombligo surgió el espacio,

De su cabeza se desarrolló el cielo,

De sus pies nació la tierra,

Y de sus orejas las regiones.

Así construyeron a los mundos (Tola, 1968, pp. 268-269)

Finalmente, la Maitri Upanishad ${ }^{17}$ (V1,1-4; V11,11 y V1, 35, citada en Coomaraswamy, 2001), compara a Brahman ${ }^{18}$ con un árbol, diciendo:

Ciertamente, hay dos formas del Brahman, a saber, con y sin semejanza. El "Eso" que es una semejanza, es el Brahman contingente; el "Eso" que es sin imagen, es el Brahman y la Luz esencial...Él asumió una Trinidad, pues el Om tiene tres

15 El término "casta" designa una institución social y religiosa que a su vez alude a dos instituciones indias: varna (color) y jati (nacimiento). Varna es una división social de alguna manera semejante a la clase social al tiempo que jati es la casta propiamente dicha. Las cuatro castas son: los brahmanes (sacerdotes), los guerreros y gobernantes o shatriyas, los comerciantes y agricultores o vaishyas y los sirvientes u obreros o sudras, división que en el presente cumple una función más que nada conceptual. Los parámetros tradicionales para su funcionamiento son: la endogamia, la comensalidad y la asociación con una profesión particular (Lorenzen y Preciado Solís, 2003). Sin embargo, como señala Banerjee (2008), conviene recordar que la casta funciona en diversas coordenadas y que la religión es solamente una de ellas, siendo una institución que atiende al proceso de negociación y adaptación de diversos elementos. Se calcula que en la actualidad hay tal vez cuatro mil castas en la India (Lorenzen y Preciado Solís, 2003).

16 Para una visión del tema de género en la época, se puede consultar Rodríguez de la Vega (2010).

17 Pertenece al grupo de las Upanishads intermedias, datadas entre los años 500 y 400, aproximadamente.

18 Brahman designa a la Realidad última. 
factores, y por estos tres factores está tejida en Él urdimbre y trama, la totalidad del mundo... El triple Brahman tiene su raíz arriba. Sus ramas son el espacio, el aire, el fuego, el agua, la tierra y el resto. A Éste se le llama la Única Higuera, y es inherente a él la energía ígnea que es el Sol Supernal...Él que está ahí, la Persona de ahí, es el Sol Supernal, mi mí Mismo soy Él.

Maillard (2001) menciona que en el contexto de la visión tradicional cosmocéntrica de la India, el término utilizado para aludir al principio que engloba los elementos naturales -agua, tierra, fuego, aire y éter- es prakrti, término que aparecerá como complementario e indisoluble de purusa, en el sistema filosófico Samkhya, aún cuando la generación, conservación y disolución del mundo corresponden al elemento femenino. Agrega que la presencia de lo femenino que rige los ciclos naturales es mayor en las culturas autóctonas, agrarias y en tal sentido, el culto a las diosas prevalece hasta la actualidad en las zonas rurales de la India.

Pujol señala que el purusa es la estructura elemental del cosmos incipiente y al desmoronarse ella, surge la multitud de formas y el hombre, por su parte, es la correspondencia estructural del purusa. El hecho de que el purusa contenga a la naturaleza y que ella penetre en el hombre anula cualquier escisión entre ambos en razón de que el hombre, como purusa cósmico es el origen de la naturaleza y como humano, lleva sus elementos en sí. De esta manera, señala: "quien esto así crea tal vez sentirá que al cortar un árbol arranca un pelo de su propio cuerpo, porque sabe que existe un vínculo secreto entre el árbol y el pelo. Si finalmente lo ha de cortar, lo hará quizás con respeto, sabiendo que lo que está cortando no es un objeto ajeno, sino una parte de su propio ser" (Pujol, 2001, p. 56).

Ello guarda relación con distintas prohibiciones canónicas en la India, tales como las de distintos Puranas ${ }^{19}$ que prohíben cortar árboles, llegando incluso en el Agni Purana, ${ }^{20}(258,25$, citado en Pujol, 2001) a decretar el castigo corporal para quien corte determinados árboles (mango, baniano, etc.). En línea con ello, en el Mahabharata ${ }^{21}$, la agricultura y la minería son consideradas actividades nocivas para la tierra.

19 Textos de literatura india aparecidos en el período Gupta (300-500 D.C.) y siglos sucesivos.

20 Contiene descripciones de diversas encarnaciones del dios Vishnu y la tradición sostiene que fue recitado por el dios Agni (Fuego) al sabio Vashista.

21 Es la gran epopeya india, que narra la lucha dinástica por el trono de Hastinapura, del reino del clan Kuru, entre los Kauravas y los Pandavas. 
Por su parte, el Jainismo ${ }^{22}$, considera al universo un organismo vivo, representado por un ser humano colosal, animado en todas sus partes por mónadas vitales que circulan por sus miembros y esferas. Dicho organismo es inmortal y las mónadas vitales imperecederas, de tal modo que ascendemos y descendemos pasando por distintos estados del ser (divino, humano, animal).

Las mónadas vitales que gozan de los estados superiores del ser -aquellas que son temporalmente divinas o humanas- tienen cinco facultades sensoriales: la facultad pensante o manas; la fuerza física o kaya-bala; la duración de la vida o ayus; el poder de la palabra o vacana-bala y el poder de respirar o svasocchvasa-bala, haciéndose la salvedad de que las ranas, peces y otros animales que no provienen del útero, no poseen la facultad de pensar, razón por la cual son considerados asañjñin -insensibles- mientras que los elefantes, vacas, cabras, leones, tigres y demás mamíferos, la poseen y por eso son considerados sañjñin -sensibles-.

Para la filosofía jaina, todo pensamiento y acto implican una acumulación de sustancia kármica y el peor delito posible es el de matar o herir a un ser vivo, por lo que la regla primordial jaina de virtud es la de no hacer mal a ninguna criatura (seres humanos, animales, plantas e incluso moléculas o átomos de materia que habitan en ellos).

De esta manera, la ingesta inadvertida de carne para un monje jaina implica que el cristal de su mónada queda manchado, como efecto mecánico de la ingesta de un ser sacrificado; en razón de ello, suelen barrer el camino con una escobilla para que sus pies no pisen ninguna criatura viva. El Budismo, en cambio, ante la misma situación, privilegiará la intención, de tal manera que el monje budista que ingiera carne sólo será culpable si la desea o si el animal ha sido sacrificado para él y tiene conocimiento de ello, privilegiándose no los hechos, sino las actitudes asumidas ante ellos, la vigilia moral (Zimmer, 1979).

El Vinaya, el Abhidharma y el Sutrapitaka ${ }^{23}$ enfatizan la intención respecto al hecho de comer carne, señalando el último que la carne es pura en los tres

22 Esta doctrina niega la autoridad de los Vedas y las tradiciones ortodoxas del Hinduismo, de fuentes ario-brahmánicas y toma creencias pre-arias. Se considera que Mahavira es su iniciador histórico (Zimmer, 1979).

23 La literatura mencionada se relaciona a los distintos períodos históricos del Budismo: 1) El período del Budismo primitivo, en que Buda predica su doctrina hasta alrededor el 350 A.C. y la Comunidad Budista se empieza a dividir en sectas, 2) Período del Budismo Hinayana, desde 350 A. C. hasta el siglo I D. C. La mayoría de las sectas constituye su canon propio compuesto por: a) Sutrapitaka, que contiene Sutras, b) Vinayapitaka, que alude a la disciplina y c) Abhidharmapitaka, que contiene textos de elaboración y sistematización de doctrinas del Sutrapitaka y 3) Período del Budismo Mahayana, desde el siglo I D. C. hasta nuestros días. Aparecen en este período las sectas mahayanistas, cuyas doctrinas se apartan de aquellas del Budismo Hinayana. (Tola y Dragonetti, 1980) 
sentidos, cuando el monje no ha visto ni oído que la carne que le ofrecen es de un animal matado para él y no tiene razones para suponerlo. El Dighanikaya ${ }^{24}$, en cambio, solamente especifica que Buda se abstiene de comer carne cruda.

En el Budismo Mahayana ${ }^{25}$, el vegetarianismo, parece tener una relación mayor con karuna (compasión) y maitri (benevolencia) que con ahimsa, en algunos textos en particular, esta idea parece tener estrecha relación con la teoría del tathagatagarbha -esencia de Buda que existe en todos los seres- (Seyfort Ruegg, 1993-1994). Dados los problemas que tales prescripciones pueden ocasionar a los practicantes, sobre todo los laicos, el Mahayana contempla prácticas para liberar el "mal karma" que cualquier violación de lo prescripto pudiese ocasionar, pero ello a su vez, reduce el peligro de las inhibiciones.

Es decir que tanto para el Budismo como para el Jainismo, matar o causar algún daño a los seres vivos se consideraba malo e inmoral porque provocaba un mal karma y porque todos los seres vivos y conscientes tienen igual temor a la muerte y rechazo al dolor que los humanos (Schmidthausen, 1991).

Aún cuando se veía a los animales, en general, como más violentos y menos sabios, dentro del samsara ${ }^{26}$ no existe una distinción definitiva o permanente entre los seres que se hallan en estos dos cursos de existencia (gatti), por lo que resulta obligatorio para los seres humanos relacionarse con los animales basándose en la misma ética con que se relacionan con otros seres humanos (Mc Dermott, 1992-1993).

En la India antigua, no solamente hombres y animales se consideraban seres vivos y conscientes, sino también las plantas, las semillas, el agua y la tierra.

Mientras que la situación se mantuvo igual respecto a los animales, el Budismo debilitó su posición en lo que atañe a las plantas, la tierra y el agua en tanto no existe una fuente que afirme que dañar a las plantas o cavar la tierra constituye un mal karma ni que declare a las plantas, el agua y la tierra, como seres conscientes y vivos, aunque cabe aclarar, que tampoco existe un enunciado explícito que señale a las plantas como seres no conscientes y sí encontramos la prohibición de

24 Este texto corresponde al Sutrapitaka y contiene treinta cuatro sutras. Es un texto importante del canon Pali, de la secta de los Theravadins, del Budismo Hinayana, siendo éste el único canon budista conservado totalmente y en su lengua india original (Dragonetti y Tola, 2005).

25 El consumo o no de carne entre los mahayanistas estuvo influenciado entre otros, por factores geográficos, el Vinaya usado por el grupo considerado que reforzaba las enseñanzas filosóficas, etc. (Seyfort Ruegg, 1993-1994).

26 El término samsara designa esencialmente el ciclo de reencarnaciones y también la realidad empírica (Tola y Dragonetti, 1983). 
dañar plantas y semillas, entre los monjes y monjas. Sin embargo, antiguos textos canónicos, mencionan en relación a la actitud espiritual de la no agresión, a los seres móviles e inmóviles (las plantas).

Las inhibiciones sobre hacer daño a las plantas no se dejaron de lado completamente y en tal sentido, el Budismo aceptó la creencia popular de que las plantas, y de modo particular los árboles grandes, están habitados por espíritus y divinidades. Existen algunas pocas fuentes en que se justifica la prohibición que rige sobre los monjes acerca de destruir plantas en razón de que ellas son morada de animales pero, a pesar de ello, parece haberse puesto mayor énfasis en los seres individuales, especialmente los animales y en el daño directo o el dar muerte (Schmidthausen, 1991).

Es a partir del Budismo y su prédica de no-violencia que ahimsa queda incorporado a la cultura de la India (Tola y Dragonetti, 2004) y, dado el peso de la ética en el Budismo, ahimsa aparece mencionada junto a otras cualidades, en distintos textos como el Dhammapada ${ }^{27}$, los Jatakas ${ }^{28}$, el Udana ${ }^{29}$, etc., incluso aparece mencionada en relación a Buda, en el Gita Govinda, donde éste es referido como uno de los avatares del dios Vishnu, que se opone a los sacrificios prescriptos por los Vedas ${ }^{30}$.

27 En el Dhammapada XVI, 185, se dice: "Abstenerse de vituperio, abstenerse de hacer daño, el autodominio según los preceptos del Patimokha, la moderación en la comida, una vida solitaria y dedicarse a la concentración: éste es el mensaje de los Budas (buda)" (Dragonetti, 1995, p. 148).

28 El Jataka N 18, "El banquete en honor de los muertos", dice: "Si los seres supieran al menos que el castigo será renacer para sufrir, un ser vivo no mataría a otro ser vivo. Tremendo es el destino del que mata". El Jataka N 181, "El príncipe sin par", dice: "El Príncipe sin Par, poderoso arquero, que lanzaba sus flechas a lo lejos, que podía dar con el dardo en el ojo del buey, que dispersaba a grandes ejércitos, enfrentándose a todos sus enemigos, sin embargo a ninguno mató. Salvó a su hermano y alcanzó el auto-control" (Tola y Dragonetti, 2003, pp. 31-34).

29 En Udana 3, "La violencia", el Bhagavant, dice: "Todos los seres desean su propia felicidad. Aquel que buscando su propia felicidad les hace daño con violencia, aquél no alcanza su felicidad después de la muerte. Todos los seres desean su propia felicidad. Aquel que buscando su propia felicidad, no les hace daño con violencia, aquél alcanza su felicidad después de la muerte" (Dragonetti, 2002, pp. 85-86).

30 En el Gita Govinda i, 13, se dice: "Tomaste el cuerpo de Gautama Buda, oh, Keshava, y criticaste las prescripciones de los Vedas, que disponen sacrificios, que ordenan matanzas de animales" (Tola, 1971, p. 27). 
Asícabe señalar, que en el Budismo, la ley delacausalidad (pratityasamutpada) ${ }^{31} \mathrm{y}$ su corolario, la de la interdependencia universal ${ }^{32}$, constituyen la base de la solidaridad entre los seres vivos, la naturaleza no consciente y las cosas (Tola y Dragonetti, 2002).

También numerosos mitos y creencias populares indios dan cuenta de la presencia de la naturaleza en el surgimiento y distintos aspectos de la vida. Zimmer (1997), menciona que la tradición popular india abunda en personajes divinos y genios, guardianes domésticos, los yaksas- genios que representan las fuerzas del suelo y minerales- reyes serpiente (naga y nagini) que personifican y gobiernan las aguas terrenales, las diosas de los ríos sagrados (Ganges, Yamuna y Sarasvati), las diosas del mundo vegetal, los elefantes sagrados, etc. Vatsyayan (2001) refiere la idea de que la vida emerge de las aguas eternas que contienen la potencia del fuego y ambos se transforman en las formas del mundo; Zimmer (1997) nos recuerda el mito de Indra, quien mató al gigantesco dragón oculto en las montañas, que retenía las aguas del cielo, dejando que ellas se liberaran, regando campos y bosques, etc.

En el presente, el Hinduismo considera a ahimsa (no violencia), una virtud elevada y al respecto, Radakrishnan (1955) sostiene que: "Ahimsa es abstención de himsa, o violencia, que es causa de dolor y sufrimiento en las criaturas conscientes, hombres o animales..." (p. 78) y agrega:

En los asramas, o ermitaños del bosque, prevalecía un espíritu de cordialidad hacia los hombres y los animales. Pero no podemos decir que las Escrituras hindúes nos exijan evitar en absoluto el uso de la fuerza. La concepción hindú no defiende obstinadamente un ideal alejado de nuestras posibilidades, aunque condena todos los compromisos. Lo divino no se encuentra separado de la vida común.[...] El uso injustificable de la fuerza es lo que constituye la violencia ${ }^{33}$ (p. 78).

31 Esta ley puede condensarse en la fórmula "asmin sati, idam bhavati", es decir: "dado esto, ocurre aquello". Nada ocurre azarosamente sino como efecto de una multiplicidad de causas (Tola y Dragonetti, 2002).

32 La causalidad que gobierna la existencia empírica implica la interdependencia de todo lo existente (Tola y Dragonetti, 2002).

33 Resulta interesante mencionar el planteo que sobre la violencia hace el texto de la Bhagavad Gita, que la concibe como un deber moral para el guerrero, con dos restricciones: a) la intención de quien realiza el acto violento (la defensa de seres o de valores) y b) la actitud mental de desapego que debe tener quien lleva a cabo ese acto violento. Así, como señalan (Tola y Dragonetti, 2003a), la violencia es incorporada en el sistema moral. 
Miguel de Mora (2001) recuerda el principio de ahimsa no solamente en relación al Jainismo sino al materialismo ateo o Lokayata ${ }^{34}$, también opuesto al sacrificio de animales, aunque cabe decir que por otras razones, dado que el materialismo consideraba que los actos de caridad y sacrificio no producen ningún mérito, en tanto las acciones no tienen efectos morales, el karma no existe, del mismo modo que no existe un alma y la muerte, es el fin de nuestra existencia (Lorenzen y Preciado Solís, 2003).

Por lo demás, el Tantrismo, exalta la energía femenina (Shakti) como la hacedora, relacionada con la producción de la naturaleza y propone otra perspectiva del anhelo de unidad ${ }^{35}$.

Vatsyayan (2001) sostiene que la tierra, el agua y el árbol son la base para los tres tipos de diosas y mujeres tanto en el arte como en el mito y mantienen el equilibrio del cosmos. Agrega que la relación árbol-mujer es predominante en el mito indio y que el motivo más significativo de mitos y esculturas indias es la vrksika (yaksi, surasundari, etc.), término que alude a criaturas de tierra, agua, plantas y de los humanos, que aparecen "de pie apoyadas contra los árboles, los abrazan y de este modo se convierten en un aspecto del árbol expresando la interpretación de la planta y del ser humano. El árbol depende de la mujer para su fertilidad, al igual que ésta depende del árbol" (p. 103). Menciona que aparecen en el arte indio del período Maurya ${ }^{36}$ temprano (siglo 11 A. C.) y en la época medieval, que también se mencionan en la literatura clásica sánscrita y la obra de Kalidasa, el Malavikagnimitra ${ }^{37}$, que gira en torno a la ceremonia de la mujer y el árbol. Dado que el árbol asoka posee propiedades medicinales para algunas enfermedades femeninas; el mito, dice, "invierte las funciones y hace que el abrazo de la mujer

34 Su principal representante fue Ajita Kesakambala, uno de los maestros más antiguos del materialismo en India. Esta escuela recibió diversos nombres, además de Lokayatas, a saber: Charvakas, Barhaspatyas, Bhutavadins y Nastikas. Su doctrina sostiene que todo tiene su origen en la materia, incluso la conciencia; niega la existencia del alma, de la Liberación, de Dios, de la vida post mortem, del Karma y el valor moral de la acción y afirma que el placer sensual es el único objetivo a perseguir por parte del hombre. El hombre se reduce a un conjunto de elementos materiales que, a su muerte, retornan a sus fuentes originarias sin dejar nada tras de sí. Por todo ello se opuso al Brahmanismo y Budismo y se presentó como el más heterodoxo de los llamados "Maestros del Error", grupo en el que se lo incluye en el Samaññaphalasutta, texto del canon budista ( Tola y Dragonetti, 1978, pp. 136-139).

35 Se puede consultar Biardeau (2005); Lorenzen y Preciado Solís (2003); Varenne (1985), etc.

36 El imperio Maurya fue el primer gran imperio unificado de la India, extendiéndose, aproximadamente, entre 320 A. C. y 185 A. C., sobre el norte y centro de India.

37 La obra narra los amores del rey Agnimitra y la Malavika. 
sea esencial para que florezca el árbol asoka: de ahí la palabra asoka dohada o el término genérico salabhanjika (la que se reclina sobre el árbol)" (p. 104).

Finalmente, Narayanan retoma la literatura de los Puranas, que focalizan en el dharma (conducta correcta) y menciona que en el Kurma Purana ${ }^{38}(1,27,16$ 57, citado en Narayanan, 1997) se advierte sobre los tiempos en que vivimos: “...luego la ambición y la pasión se levantaron nuevamente en todos lados, inevitablemente, debido al propósito predestinado de la Edad Tetra [Tercera]. Y las personas confiscaron/ tomaron los ríos, campos, montañas, grupos de árboles e hierbas, conquistándolos por fuerza", lo cual señala el inicio de la declinación de la virtud y la conducta ${ }^{39}$.

$\mathrm{Y}$ en el Matsya Purana ${ }^{40}$, la diosa Parvati responde a los dioses ante su pregunta de qué sentía ella cuidando árboles como hijos? Y ella responde:

Uno que cava un pozo de agua donde hay poco agua vive en el cielo por tantos años como gotas de agua hay en el pozo. Un depósito grande de agua es mejor que diez pozos. Un hijo es como diez depósitos grandes y un árbol es igual a diez hijos. Esa es mi norma/ mi estandarte y protegeré el universo para salvaguardarlo (Capítulo 154: 506-512, citado en Narayan, 1997).

\section{Chipko Andolan}

La plantación de árboles es recomendada por numerosos textos y su tala condenada por la mayoría de los Dharma Shastras ${ }^{41}$ y ello parece encontrar

38 La cita textual aludida por el autor en el texto mencionado, en inglés, es la siguiente: "... Then greed and passion arose again everywhere, inevitably, due to predestined purpose of the Treta [Third] Age. And people seized the rivers, fields, mountains, clumps of trees and herbs, overcoming them by strength."

39 La literatura védica distingue cuatro yugas o eras, a saber: Satya Yuga (la Era de la Verdad), Treta Yuga, Dvapara Yuga y Kali Yuga (Era de Hierro). Desde la Era de la Verdad hasta Kali Yuga, que se corresponde a los tiempos actuales, hay una marcada declinación de la virtud y de su práctica, en cuya descripción abundan distintos textos.

40 La cita textual aludida por el autor en el texto mencionado, en inglés, es la siguiente: "One who digs a well where there is Little water lives in heaven for as many years as there are drops of water in it. One large reservoir of water is worth ten wells. One son is like ten reservoirs and one tree is equal to ten sons (dasa putra samo druma). This is my standard and I will protect the universe to safeguard it..."

41 Estos textos son textos de jurisprudencia y ética hindú, que abordan cuestiones relativas a las fuentes del dharma (ley propia). De entre ellos, Las Leyes de Manu es uno de los textos más conocidos. 
correlato en distintas direcciones, entre las que encontramos el caso de Chipko Andolan. Uno de ellos es el conocido como la "masacre de Khejarli", en que Amrita Devi y otros cientos de mujeres murieron defendiendo los árboles de la zona de Rajastan, cientos de años atrás; otro, el de la flora de las colinas de Parasnath, en Bihar, salvadas por la fe y conducta jainista; otro, la iniciativa del Templo de Tirumala Tirupati, en Andhra Pradesh, que alienta a sus seguidores a llevarse a su casa árboles pequeños, jóvenes, en carácter de prasada ${ }^{42}$, etc. (Narayanan, 1997).

El movimiento Chipko Andolan captó la atención en 1973, en la ciudad de Mandal, en Uttarakhand, siendo su imagen más difundida la de las mujeres aldeanas que abrazaban los árboles ante el peligro de que fuesen a ser derribados, en tanto su tala no solamente perjudicaba el medioambiente sino también que los beneficios de tal explotación no llegaban a los aldeanos, uniendo la resistencia no violenta con la defensa de la naturaleza (Karan, 1994; Singhal y Lubjuhn, 2010; Weber, 1987-1988). Weber lo señala como el grupo de acción más celebrado de la India.

Las semillas del accionar del movimiento se expandieron y en enero de 1974, otro grupo de mujeres replicó las acciones, guiadas por Gaura Devi, salvando el bosque de Reni, en la zona del río Alaknanda, uno de los principales tributarios del río Ganges, en medio de cánticos que rezaban: "Este bosque es el hogar de nuestras madres; lo protegeremos con toda nuestra fuerza" (Singhal y Lubjuhn, 2010, p. 91).

Lideraban este movimiento Chandi Prasad Bhatt, marxista, fundador de Dasholi Gram Swarajya Sangh, grupo precursor de Chipko, y Sundar Lal Bahuguna, activista de inspiración gandhiana. Ambos movilizaron a muchos a través de diferentes intervenciones escritas, entrevistas, etc.

Así, cuando enteradas de que alguien venía a talar árboles, las mujeres de las distintas aldeas cantaban canciones relativas a la situación y juntando sus manos, abrazaban los árboles para protegerlos de su tala, tornando inútil la tarea de quienes venían a cumplir ese objetivo.

Rápidamente el movimiento se relacionó con la espiritualidad y empezaron a organizarse encuentros de plegarias en los bosques (Bhagwad katas), con énfasis en la idea de que distintas deidades residen en todo lo viviente, incluyendo los árboles, de modo que proteger los árboles se constituía en un acto sagrado.

$\mathrm{Su}$ tarea se popularizó en distintos ámbitos, al tiempo que los seguidores de Gandhi, enfatizaron su accionar a través de protestas simbólicas, entre ellas, la

42 El término "prasada" (favor/ concesión de la deidad) alude a una fruta o porción de comida bendita que se entrega a los peregrinos de los templos, para llevarse a sus casas. 
realización de padayatras ${ }^{43}$ (marchas rituales) y que el movimiento feminista enfatizó la explotación de las mujeres rurales asociándola a la de la naturaleza, etc.

Las acciones del grupo ayudaron a incluir la temática en la agenda política y en los 80, Indira Gandhi ordenó una prohibición de tala de árboles por quince años, mil metros sobre el nivel del mar en la zona de los bosques del Himalaya, que luego se extendería a las zonas boscosas de Ghat Occidental y las montañas Vidhya (Singhal y Lubjuhn, 2010). De igual manera, Chipko inspiró otros movimientos, como Appiko, del sur de India (Swain, 1997).

A través de los años, la tarea del movimiento se ha tornado más influyente y más conocida alrededor del mundo, al tiempo que incursionó en otras temáticas tales como la migración de los hombres desde las montañas al llano en busca de trabajo y el creciente y desgastante trabajo que las mujeres de las zonas montañosas debían/deben enfrentar tras la desaparición de las reservas forestales (Weber, 1987-1988).

Hacia 1976, Bahuguna consideró que el movimiento en su forma previa, ya no existía. La devastación continuó, con distintos efectos. En la actualidad, Dasholi Gram Swarajya Sangh (DGSS) lleva adelante el programa de reforestación voluntaria más importante de la India, al tiempo que Bahuguna, inclinado hacia la visión gandhiana de la autosuficiencia rural, declaró que Chipko pasó de considerar que "ningún árbol sería cortado hasta encontrar las necesidades de los pobladores locales" a "salvar los árboles para salvar la humanidad", tomando él, en 1978, el compromiso de dedicarse a la protección del ambiente en los Himalayas (Weber, 1987-1988).

\section{Notas finales}

Sin duda puede decirse que desde distintas perspectivas, en la India está presente la idea de una estrecha relación entre el micro y el macro-cosmos, y en muchos casos, ello permite aludir al carácter sagrado de la Tierra, lo que Tomalin (2004) señala como "biodivinidad", cuyo correlato en las tradiciones no teístas está dado en la concepción de cierto tipo de conciencia de los seres vivos en general que los hace sensibles al dolor, a cualquier sufrimiento, etc. y que obliga éticamente a los seres humanos en su trato con ellos. Sin embargo, acordamos con ella en que eso no necesariamente coincide con la conciencia práctica que actúa sobre el medioambiente en la actualidad, ni desde las instituciones ni desde

43 Cabe recordar la marcha épica de Chipko, atravesando el Himalaya desde Srinagar, en Kashmir, a Kohima, en Nagaland (Weber, 1987-1988). 
los individuos, es decir, cabe distinguir entre esa biodivinidad que distintas tradiciones asignan a la naturaleza (y su correlato en tradiciones no teístas) y el medio ambientalismo religioso ${ }^{44}$ que supone la aplicación consciente de tales creencias a los temas ambientales. Más aún, cabe incluso tener presente los posibles usos políticos que pueden hacerse de esta perspectiva, recordando que Tomalin (2004) ejemplifica la campaña contra el Tehri $\mathrm{Dam}^{45}$, aprovechada por la derecha hindú que usó la excusa ambientalista para establecer un ámbito más de disputa con los islámicos ${ }^{46}$.

En el marco del Ecofeminismo ${ }^{47}$, Plant (1999) sostiene que previo a la mecanización del mundo, la tierra era considerada femenina y un ser vivo, por lo que no podía justificarse la violencia en su contra, pero una vez modificada esa metáfora orgánica por una mecánica, pudo justificarse su dominio (y la violencia consecuente). Vandana Shiva (1997) considera que ha sido la dicotomía naturalezacultura la que ha permitido dominar, subyugar lo natural y dar lugar a lo que llama un "mal desarrollo", fundado sobre una idea de la naturaleza como inerte y desconectada del ser humano frente a lo que propone la vuelta a una continuidad ontológica entre naturaleza y cultura. Señala que "la recuperación del principio femenino permite trascender los cimientos patriarcales del mal desarrollo y transformarlos" y continúa, "es un proyecto político, ecológico y feminista [...], que legitima la vida y la diversidad y que quita legitimidad al conocimiento y la práctica de una cultura de la muerte que sirve de base a la acumulación de capital" (Shiva, 2004, par. 10). Por su parte, Mies (1997) considera que resulta necesaria una nueva ciencia en la que el conocimiento surja de una visión empática con todo lo vivo. Así, el Ecofeminismo propone reencantar la naturaleza al tiempo que enfatiza la diversidad ontológica de la que los seres humanos somos parte y señala que nuestra libertad se desarrolla en el marco de la biodiversidad, es decir, tenemos responsabilidades éticas con la naturaleza en tanto seres naturales.

Agarwal (1992) señala que los bosques han sido siempre significativas fuentes de vida, especialmente para los grupos tribales y proveyeron las bases para el cultivo, la caza y la recolección de productos, estimando que treinta millones de personas o más, en la India, dependen de ellos para vivir.

44 Tomalin (2004) señala también que el origen del medio ambientalismo religioso es un fenómeno moderno que no se remonta más allá de la década del '60.

45 Tehri Dam, es una represa multipropósito.

46 Al respecto, se puede consultar Sharma (2009), entre otros.

47 Se puede consultar Carcaño Valencia (2008); Leff (2004); Mellor (2000), etc. 
Señala también que la disponibilidad de los recursos naturales en el país para las personas pobres se ha ido erosionando en razón de la degradación creciente de los mismos - tanto en cantidad como en calidad- y en la apropiación de ellos por parte del Estado y/ o de agentes privados, con la consecuente declinación de lo que anteriormente era comunal. Ello, obviamente, tuvo/ tiene consecuencias de clase y género, atendiendo a las divisiones del trabajo por género (mujeres pobres y de grupos tribales hacen mucha de la recolección de productos en bosques, ríos, etc., al tiempo que tienen gran responsabilidad en la subsistencia familiar), por las diferencias en la distribución de recursos de subsistencia en los hogares rurales y porque hay grandes desigualdades entre hombres y mujeres en cuanto al acceso a los recursos productivos críticos en economías rurales, tierras para agricultura, etc. Las mujeres pobres, rurales, han sido/ son las más perjudicadas en este contexto y las que participaron de modo más activo en estos movimientos ecológicos.

Finalmente, en el caso particular de Chipko, el término mismo se ha convertido en un resguardo para cualquier actividad no violenta en defensa de los bosques o del medioambiente en general, permitiéndonos repensar las relaciones entre las personas, los géneros y lo no humano, al tiempo que re-conceptualizarlos y también, ver nuestras actitudes hacia cada uno de ellos (de hecho, Agarwal señala que Chipko tiene el potencial de convertirse en un movimiento en contra de las desigualdades de género). Chipko ha marcado la conciencia no solamente de la India sino del mundo, permitiéndonos también resignificar los planteos de textos antiguos que abordan la profunda imbricación de los seres en el planeta, porque, como sostiene Panikkar (citado en Maillard, 2001), en vez de una ecología hace falta una ecosofía.

La visión de la realidad es la visión que la realidad tiene en nosotros; es llegar a ser real. Éste es el acto humano, participar en la palabra creadora como los Vedas nos recuerdan (RV 11, 164, 37). La visión de la realidad no son nuestras nuevas o viejas perspectivas acerca de lo real, sino la visión que la realidad misma revela en mí (Panikkar, 2001, p. 47).

\section{Referencias bibliográficas}

Agarwal, B. (1992). The Gender and Environmental Debate: Lessons from India. Feminist Studies, 18 (1), 119-158.

Banerjee, I. (2008). ¿Existe un sistema de castas? Estudios de Asia y África, XL111 (2), 325-381. 
Biardeau, M. (2005). El Hinduismo. Antropología de una civilización. Barcelona: Kairós.

Carcaño Valencia, E. (2008). Ecofeminismo y ambientalismo feminista. Una reflexión crítica. Argumentos, 21 (56), 183-188.

Coomaraswamy, A. K. (2001). El árbol de la vida, el loto de la tierra y la rueda de la palabra. En El Árbol de la Vida. La Naturaleza en el Arte y las Tradiciones de la India (pp. 125-157). Barcelona: Kairós.

Dragonetti, C. (1995). Dhammapada. La esencia de la sabiduría budista. Buenos Aires: Editorial Sudamericana.

Dragonetti, C. (2002). Udana. La palabra de Buda. Buenos Aires: mmYin-shun Foundation, New Jersey, USA- Fundación Instituto de Estudios Budistas.

Dragonetti, C. y Tola, F. (2004). Dhammapada. La esencia de la sabiduría budista. New Jersey: Primordia.

Dragonetti, C. y Tola, F. (2005). Digha Nikaya. Diálogos mayores de Buda. New York: Fundación Instituto de Estudios Budistas FIEB, Argentina- The Buddhist Association of the United States.

Jain, S. K. Some aspects of biodiversity and Indian traditions. Indian Journal of History of Science, 33 (1), 51-62.

Karan, P. P. (1994). Environmental Movements in India. Geographical Review, 84 (1), 32-41.

Leff, E. (2004). El ecofeminismo: el género del ambiente. Polis, 3 (9).

Lorenzen, D. N. y Preciado Solís, B. (2003). Atadura y Liberación. Las religiones de la India. México: El Colegio de México, Centro de Estudios de Asia y África.

Maillard, Ch. -ed.- (2001). El Árbol de la Vida. La Naturaleza en el Arte y las Tradiciones de la India. Barcelona: Kairós.

Mellor, M. (2000). Feminismo y Ecología. México: Siglo XXl. 
Mies, M. y Shiva, V. (1997). Ecofeminismo. Teoría, crítica y perspectivas. Barcelona: Icaria.

Moncó, S. (1999). Mujeres en los Vedas (Himnos del Rig Veda y el Atharva Veda). Madrid: Sofía Moncó-Akal Ediciones.

Mc Dermott, J. P. C. (1992-1993). Animales y humanos en el Budismo Primitivo. Revista de Estudios Budistas, 4, 31-48.

Narayanan, V. (1997). "One Tree Is Equal to Ten Sons": Hindu Responses to the Problems of Ecology, Population, and Consumption. Journal of the American Academy of Religion, 65 (2), 291-332.

Olañeta, J.J.-ed.- Himno a la Tierra. Prthivisukta. Palma de Mallorca: J.J. Olañeta-Índica Books.

Panikkar, R. (2001). El Toque Contemplativo. En El Árbol de la Vida. La Naturaleza en el Arte y las Tradiciones de la India (pp. 45-48). Barcelona: Kairós.

Plant, J. (1999). Ecofeminismo. En Pensamiento verde: una antología (pp. 112115). Madrid: Ed. Trotta.

Pujol, O. (2002). Naturaleza y culto. En El Árbol de la Vida. La Naturaleza en el Arte y las Tradiciones de la India (pp. 49-68). Barcelona: Kairós.

Rodriguez de la Vega, L. (2010, noviembre). Religión, poder y género en la India del Siglo V1 A.C. Documento presentado en las V1 Jornadas Ciencias Sociales y religión. V reunión Científica CLACSO. "Religiones, Sexualidades y poder". Buenos Aires, Argentina.

Rodríguez de la Vega, L. (2008, octubre). La crítica a las tradiciones brahmánicas en la India del siglo Vl y su impacto. Documento presentado en el 111 Congreso Nacional de ALADAA "Repensar el concepto de frontera cultural-étnica y política en Asia y África”. Universidad Nacional del Comahue, Neuquén, Argentina.

Schmidthausen, L. (1991). Budismo y Naturaleza. Revista de Estudios Budistas, $1(1), 63-85$. 
Seyfort Ruegg, D. (1993-1994). Ahimsa y el vegetarianismo en la historia del Budismo. Revista de Estudios Budistas, 6, 47-61.

Sharma, M. (2009). Passages from Nature to Nationalism: Sunderlal Bahuguna and Tehri Dam Opposition in Garhwal. Economic \& Political Weekly, XLIV (8), 35-42.

Shiva, V. (1998). Las mujeres en la naturaleza. En Ecología y feminismo (pp. 161177). Granada: Ed. Comares.

Shiva, V. (2004). La mirada del Ecofeminismo. [versión electrónica]. Polis, revista de la Universidad Bolivariana, 3 (9). Recuperado el 12 de julio de 2011, http://www.revistapolis.cl

Singhal, A. y Lubjuhn, S. (2010). Chipko Environmental Movement (India). Encyclopedia of Social Movement Media (pp. 91-92). Los Angeles: Sage Publications.

Swain, Ash. (1997). Democratic Consolidation? Environmental Movements in India. Asian Survey, 37 (9), 818-832.

Tola, F. (1968). Himnos del Rig Veda. Buenos Aires: Editorial Sudamericana.

Tola, F. (1971). Gita Govinda. Los amores del dios Krishna y de la pastora Radha. Buenos Aires: Editorial Sudamericana.

Tola, F. Y Dragonetti, C. (1978). Yoga y Mistica de la India. Buenos Aires: Editorial Kier.

Tola, F. Y Dragonetti, C. (1980). Budismo Mahayana. Buenos Aires: Editorial Kier.

Tola, F. y Dragonetti, C. (1983). Filosofía y Literatura de la India. Buenos Aires: Editorial Kier.

Tola, F. y Dragonetti, C. (1980). El Budismo Mahayana. Estudios y Textos. Buenos Aires: Editorial Kier.

Tola, F. y Dragonetti, C. (2002). La concepción budista del universo, causalidad e infinitud. Buenos Aires: Anales de la Sociedad Científica Argentina (Año 1999, Vol. 229, $\mathrm{N}^{\circ}$ 1). 
Tola, F. y Dragonetti, C. (2003a). El Budismo frente a la justificación de la violencia. En Violencia y Cultura. Nuevas propuestas para una Antropología argentina (pp. 285-303). Buenos Aires: Biblos.

Tola, F. y Dragonetti, C. (2003b). El Vedismo. Los Vedas. Lo Uno como origen de Todo. El Orden cósmico. Madrid: Separata del Boletín de la asociación Española de Orientalistas. Año XXX1X.

Tola, F. y Dragonetti, C. (2003c). Vidas anteriores de Buda. Jatakas. New Jersey: Primordia.

Tola, F. y Dragonetti, C. (2004). Budismo. Unidad y Diversidad. New York: Fundación Instituto de Estudios Budistas-FIEB-The Buddhist Association of the United States.

Tomalin, E. (2004). Bio-Divinity and Biodiversity: Perspectives on Religion and Environmental Conservation in India. Numen, 51 (3), 265-295.

Varenne, J. (1985). El Tantrismo o la sexualidad sagrada. Barcelona: Kairós.

Vatsyayan, K. (2001). La Ecología y le mito indio. En El Árbol de la Vida. La Naturaleza en el Arte y las Tradiciones de la India (pp. 90-110). Barcelona: Kairós.

Weber, Th. (1987-1988). Is there still a Chipko Andolan? Pacific Affairs, 60 (4): 615-628.

Wilkins, W. J. (1987). Mitología Hindú. Barcelona: Edicomunicación.

Zimmer, H. (1979). Filosofías de la India. Buenos Aires: EUDEBA.

Zimmer, H. (1997). Mitos y simbolos de la India. Madrid: Ediciones Siruela. 